\title{
Wavelengths of Rotational Lines in the Water-Vapor Bands at 0.93 and 1.13 Microns
}

\author{
C. C. Kiess
}

\begin{abstract}
The infraied water-vapor bands at 0.93 and 1.13 microns have been photographed with the grating spectrographs of the National Bureau of Standards. These bands appear in absorption in the continuous spectrum of white-light sources, part or all of the optical path being in air. They appear also in emission in the spectra of flames containing hydrogen and oxygen compounds. In relatively short light-paths, the rotational lines of these bands are sharp and show little or no tendency toward diffuseness, even in air for which the relative humidity is 90 percent. Their wavelengths may be measured with accuracy on high-dispersion spectrograms. Wavelengths, estimated intensities, and wave numbers, as derived from the spectrograms, are presented. The wavelengths are recommended for use in calibrating infrared spectrometers.
\end{abstract}

\section{Introduction}

Among the outstanding features in the near infrared solar spectrum are the bands due to absorption by the water vapor in the earth's atmosphere. Between $9000 \mathrm{~A}$ and the limit photographically attainable at $13500 \mathrm{~A}$ there are several bands that make up the groups of lines designated by the symbols $\rho, \sigma, \tau$, and $\Phi$ on Langley's normal map of the solar spectrum [1]. ${ }^{1}$ These, and other absorption features, beyond the visible limit in the red, have been observed frequently ever since the discovery of the infrared region of the spectrum by Sir William Herschel in 1800 [2]. However, it was not until 70 years later that their telluric origin was established by Lamansky [3], who observed their fluctuations in intensity with altitude of the sun and humidity of the atmosphere. Subsequently, this behavior of the bands was verified when Abney and his collaborators made the first photographs of the near infrared spectrum of the sun. In 1883 Abney and Festing [4] reported that at a high altitude on a dry day the banded absorption between 9420 and 9800 A nearly disappeared from the sun's spectrum. At such times, according to these authors, the strengths of the bands, as they were observed on humid days, could be restored to the solar spectrum by placing a water-cell in front of the slit of the spectrograph. Control observations of an artificial source through cells of water 3 and 12 inches thick revealed the same "water bands". But these observers were reluctant to attribute them to the absorption of water vapor because the "Fraunhofer lines in the band are irregularly distributed through the band ... and do not spread out as the darkness of the band increases". However, it is known now that the absorptions of liquid water and its vapor are not the same, and therefore the general or continuous darkness, observed in Abney and Festing's experiments with the water-cells, is not to be confused with the selective absorption of the vapor.

Although the origin of the bands in the absorption of water vapor was long suspected the fact was established beyond doubt only in 1918 by Hettner

\footnotetext{
1 Figures in brackets indicate the literature references at the end of this"paper.
}

[5], who observed the radiant energy from a Nernst glow lamp through a column of water vapor. He placed the maxima of the bands at $0.94 \mu$ and 1.128 $\mu$, respectively, noting that previously Fowle [6] had detected a depression at $1.13 \mu$ in the $\Phi$ band of the solar spectrum. Except for the photographic method of Abney, which apparently was not successful in the hands of later investigators, the only way of studying the bands was with radiometric devices of various kinds. Observations of this kind, with the low dispersions employed, usually delineate the outline of the bands without yielding much information about their finer structure.

The first photographic recording of the $\rho, \sigma, \tau$ bands, since the days of Abney, was made more than 30 years ago by Meggers [7]. With the plane grating spectrograph of the Johns Hopkins University, Meggers photographed the sun's spectrum from 6800 to $9600 \mathrm{~A}$ on ordinary plates sensitized with dicyanin. A few years later Burns [8], and then Brackett [9], again by using plates sensitized with dicyanin, were able to extend the sun's spectrum to nearly 9900 A. Both these observers noted the variable intensity of some of the strong lines near $9300 \mathrm{~A}$ and suggested that terrestrial water vapor was very probably the cause of their appearance and behavior.

About 25 years ago, when new photosensitizers became available, it was possible to record spectra photographically with high dispersion; first out to $11000 \mathrm{~A}$, later out to $13000 \mathrm{~A}$, with the same precision as that used for the shorter wavelength regions. At the National Bureau of Standards [10] the work of extending our knowledge of the infrared emission spectra was undertaken on about 50 chemical elements. One of the first fruits of these new investigations was the recognition of the water-vapor absorption bands superimposed on the continuum that usually accompanies the emission lines and bands in the spectra of arcs between metallic electrodes. Their nuisance value in a study of emission-line spectra was soon felt when it was realized that errors of wavelength and intensity afflicted all lines that were blended partially or almost completely with the absorption lines. Therefore, it became important 
to determine the wavelengths and intensities of these lines so that their effect on nearly coincident atomic and molecular emission lines could be estimated.

In recent years, however, the importance of these bands has been felt in other branches of spectroscopy. In the investigation with infrared spectrometers of various flames containing hydrogen and oxygen compounds, these bands and others, due to the $\mathrm{H}_{2} \mathrm{O}$ molecule, appear in emission with intensities proportional to the temperature of the flame. In experiments on the absorption of liquids and vapors, they appear as sharp absorption lines in the continuous spectrum of the source, if the spectrometer is filled with air containing moisture. These facts have led to the suggestion by Plyler [11] that the bands be used as standards in the calibration of infrared spectrometers, particularly of grating spectrometers in which the shortward regions of overlapping orders can be used to calibrate the longward first-order spectrum, in which reliable standards are still lacking. The allocation of the lines to the $P, Q$, and $R$ branches of the bands in the vibrationrotation spectrum of the $\mathrm{H}_{2} \mathrm{O}$ molecule was first carried through by Mecke and collaborators [12], who interpreted the spectrum on the basis of the unsymmetrical rotator. The wavelengths used by them for the bands at 0.93 and $1.13 \mu$ are those measured by Lueg and Hedfeld [13]. This earlier work on the analysis of the bands was later revised and extended by Benedict [14].

\section{Experimental Details}

In order to secure spectrograms of the water-vapor bands unaffected by atomic and molecular emission features, several exposures were made to a Point-olite lamp, a very convenient source of continuous radiation. Two sets of observations were made, the first early in December 1934 when the air in the laboratory was dry (the recorded relative humidity being between 20 and 25\%); the second in July and August 1935, when high relative humidities were recorded $(90 \%$ on the July date, 50 to $57 \%$ on the
August dates). To obtain the spectrograms, two 6 -in. concave gratings of $21-\mathrm{ft}$. radius were used: one was a Rowland grating with 20,000 lines per inch, the other a Wood grating with 15,000 lines per inch. Each grating was set up in a Wadsworth mounting, in which the total light path source-tocollimator-to-grating-to-plate was approximately 11 $\mathrm{m}$. The Rowland grating, with a dispersion of 3.4 $\mathrm{A} / \mathrm{mm}$ in the first order, was used only for the band at $0.93 \mu$, whereas the Wood grating, dispersion 4.8 $\mathrm{A} / \mathrm{mm}$, was used for both bands. In juxtaposition to the water-vapor spectrum, each plate received exposures to the iron are to supply standards for the wavelength reductions. The desired order of spectrum for each exposure was secured by inserting appropriate colored-glass filters in the light path between the source and the slit. For recording the spectra, plates coated with Eastman I-M and I-Q emulsions were used. Immediately before exposure, each plate was hypersensitized in an ammonia bath according to the procedure described by Burka [15]. The bands are illustrated in figure 1.

\section{Discussion and Results}

Visual inspection of the spectrograms reveals only slight differences among those taken on dry and humid days. The latter show a few more very faint lines than do the plates taken when the air was relatively dry; but there is no indication of broadening and blending of the band lines such as occur on the solar spectrograms. The wavelengths measured on the different plates for the individual lines are in very close agreement. Therefore, the values adopted for entry in the first columns of tables 1 and 2 are the unweighted averages of the different measurements. For all the lines in table 1, except a few of the faintest, the wavelengths are the means of four measurements. Similarly, the values of nearly all the lines of table 2 are the means of three measurements. In the third column of each table are given the vacuum wave numbers of the lines as interpolated from Kayser's Tabelle der Schwingungszahlen. For

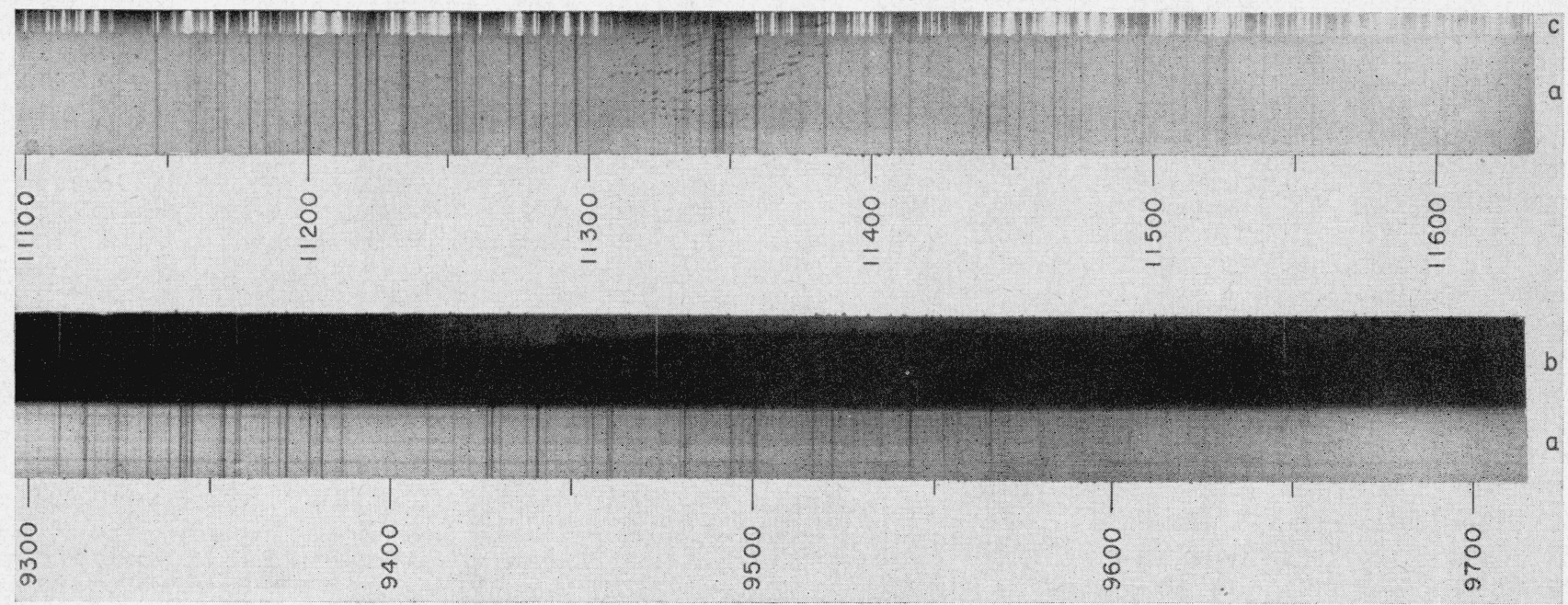

FiguRE 1. Infrared bands of water-vapor: (a) water-vapor; (b) Fe arc, 2d order; (c) Fe arc, 3d order. 
TABLE 1. Wavelengths, intensities, and wave numbers in the band at $1.13 \mu$

\begin{tabular}{|c|c|c|c|c|c|c|c|c|c|c|c|}
\hline Wavelength & $\begin{array}{l}\text { Inten- } \\
\text { sity and } \\
\text { notes }\end{array}$ & $\begin{array}{c}\text { Wave } \\
\text { number }\end{array}$ & Wavelength & $\begin{array}{c}\text { Inten- } \\
\text { sity and } \\
\text { notes }\end{array}$ & $\begin{array}{c}\text { Wave } \\
\text { number }\end{array}$ & Wavelength & $\begin{array}{l}\text { Inten- } \\
\text { sity and } \\
\text { notes }\end{array}$ & $\begin{array}{c}\text { Wave } \\
\text { number }\end{array}$ & Wavelength & $\begin{array}{l}\text { Inten- } \\
\text { sity and } \\
\text { notes }\end{array}$ & $\begin{array}{c}\text { Wave } \\
\text { number }\end{array}$ \\
\hline 11620. 26 & 1 & $\begin{array}{c}\mathrm{cm}^{-1} \\
\text { 8603. } 30\end{array}$ & $\stackrel{A}{11446.62}$ & 12 & $\begin{array}{c}c m^{-1} \\
\text { 8733. } 81\end{array}$ & 11312.35 & 1 & $\begin{array}{c}\mathrm{cm}^{-1} \\
8837.47\end{array}$ & $\begin{array}{c}A \\
11197.08\end{array}$ & 10 & $\begin{array}{c}C m^{-1} \\
8928.44\end{array}$ \\
\hline 11600. 99 & 1 & 8617.59 & 11440.47 & 50 & 8738.50 & 11298. 81 & 5 & 8848.05 & 11192.01 & 4 & 8932.49 \\
\hline 11586. 66 & 4 & 8628.25 & 11434.68 & 10 & 8742.92 & 11294. 42 & 50 & 8851.50 & 11190.85 & 7 & 8933. 41 \\
\hline 11575. 25 & 2 & 8636. 76 & 11419.03 & 5 & 8754.90 & 11290.11 & 2 & 8854. 88 & 11189. 12 & 5 & 8934.79 \\
\hline 11562. 19 & 1 & 8646.51 & 11412. 27 & 10 & 8760.02 & 11286.85 & 12 & 8857. 43 & 11187. 26 & 5 & 8936. 28 \\
\hline 11554.71 & 7 & 8652. 11 & 11405.83 & 30 & 8765.04 & 11282.14 & 12 & 8861. 13 & 11186. 16 & 20 & 8937. 16 \\
\hline 11546.74 & $i$ & 8658.08 & 11397. 41 & 1 & 8771.52 & 11275. 75 & 40 & 8866. 15 & 11180.75 & 25 & 8941. 49 \\
\hline 11541.64 & 1 & 8661. 90 & 11396. 36 & 2 & 8772.32 & 11271.02 & 15 & 8869. 87 & 11172. 16 & $10 d ?$ & 8948.36 \\
\hline 11537. 38 & 3 & 8665. 13 & 11382. 23 & 20 & 8783. 21 & 11265. 06 & 1 & 8874.56 & 11169. 73 & 15 & 8950.31 \\
\hline 11533.95 & 1 & 8667. 67 & 11373. 84 & 1 & 8789. 69 & 11259. 31 & 20 & 8879.09 & 11165.80 & 3 & 8953. 46 \\
\hline 11524.25 & 12 & 8674.97 & 11373. 26 & 1 & 8790.13 & 11254.57 & 12 & 8882.84 & 11165.02 & 1 & 8954.08 \\
\hline 11523.19 & 10 & 8675. 77 & 11358.00 & 15 & 8801.95 & 11253. 13 & 4 & 8883. 98 & 11163. 79 & 2 & 8955. 07 \\
\hline 11517. 23 & 12 & 8680.27 & 11357. 76 & 25 & 8802. 13 & 11252. 47 & 5 & 8884.50 & 11163. 06 & 1 & 8955.65 \\
\hline 11509.96 & 2 & 8685.75 & 11349. 62 & 7 & 8808.45 & 11251. 15 & 40 & 8885.54 & 11162. 29 & 5 & 8956. 27 \\
\hline 11505.37 & 2 & 8689. 21 & 11348.48 & 2 & 8809. 33 & 11248.26 & 1 & 8887.82 & 11160.36 & 2 & 8957.82 \\
\hline 11497.37 & 1 & 8695.26 & 11346.30 & 20 & 8811.02 & 11242.04 & 1 & 8892.74 & 11159.35 & 1 & 8958. 63 \\
\hline 11495. 12 & $20 d ?$ & 8696. 96 & 11345.04 & 5 & 8812.00 & 11240.67 & $<1$ & 8893. 82 & 11155. 38 & 1 & 8961.82 \\
\hline 11493.10 & 3 & 8698. 49 & 11343. 78 & 18 & 8812.98 & 11235. 17 & 25 & 8898. 18 & 11152. 03 & 4 & 8964.51 \\
\hline 11492.08 & $<1$ & 8699.26 & 11343. 26 & 1 & 8813. 38 & 11233. 98 & 5 & 8899. 12 & 11148. 91 & $20 d ?$ & 8967. 03 \\
\hline 11485.52 & $5 d ?$ & 8704.23 & 11342.54 & 4 & 8813. 95 & 11233. 30 & 7 & 8899. 66 & 11147. 97 & 1 & 8967. 78 \\
\hline 11483.78 & $<1$ & 8705.55 & 11338. 13 & 15 & 8817. 37 & 11224.92 & 25 & 8906. 30 & 11136.05 & 2 & 8977. 38 \\
\hline 11473. 12 & 15 & 8713.64 & 11337. 31 & $<1$ & 8818.01 & 11222.92 & 1 & 8907.88 & 11134.37 & 2 & 8978. 73 \\
\hline 11471.64 & 1 & 8714.76 & 11334. 29 & 2 & 8820.36 & 11221. 40 & 5 & 8909. 09 & 11128. 23 & 1 & 8983. 68 \\
\hline 11470.20 & 7 & 8715.86 & 11333. 31 & 6 & 8821.12 & 11221.14 & 20 & 8909.30 & 11126. 97 & 1 & 8984.70 \\
\hline 11467.50 & 10 & 8717.91 & 11332. 30 & 5 & 8821.90 & 11217.40 & 7 & 8912.27 & 11120.62 & 1 & 8989. 83 \\
\hline 11463. 69 & 40 & 8720.81 & 11329.64 & 2 & 8823. 97 & 11216.54 & 20 & 8912.96 & 11112.03 & 2 & 8996. 79 \\
\hline 11456.30 & 10 & 8726.43 & 11326. 99 & $<1$ & 8826.05 & 11210.62 & 18 & 8917. 66 & 11109.40 & 1 & 8998. 92 \\
\hline \multirow[t]{2}{*}{ 11451. 47} & 15 & 8730. 11 & 11321.64 & 7 & 8830.22 & 11201. 12 & 15 & 8925. 22 & 11106.00 & 1 & 9001.68 \\
\hline & & & & & & 11200.84 & 15 & 8925.45 & 11102.89 & 2 & 9004.20 \\
\hline
\end{tabular}

TABLE 2. Wave lengths, intensities, and wave numbers in the band at $0.93 \mu$

\begin{tabular}{|c|c|c|c|c|c|c|c|c|c|c|c|}
\hline Wave length & $\begin{array}{l}\text { Intensity } \\
\text { and } \\
\text { notes }\end{array}$ & Wave number & Wave length & $\begin{array}{c}\text { Intensity } \\
\text { and } \\
\text { notes }\end{array}$ & Wave number & Wave length & $\begin{array}{c}\text { Intensity } \\
\text { and } \\
\text { notes }\end{array}$ & Wave number & Wave length & $\begin{array}{l}\text { Intensity } \\
\text { and } \\
\text { notes }\end{array}$ & Wave number \\
\hline$A$ & & $\mathrm{~cm}^{-1}$ & A & & $\mathrm{cm}^{-1}$ & $A$ & & $\mathrm{~cm}^{-1}$ & $A$ & & $\mathrm{~cm}^{-} \mathrm{C}$ \\
\hline 9782.45 & 1 & 10219.60 & 9568.96 & 1 & 10447.59 & 9461.33 & 6 & 10566. 44 & 9357. 53 & 4 & 10683. 65 \\
\hline 9757.65 & 1 & 10245.56 & 9566. 63 & 7 & 10450.14 & 9460.01 & 10 & 10567.92 & 9354. 29 & 20 & 10687. 35 \\
\hline 9749.32 & 1 & 10254.31 & 9565.07 & 3 & 10451.84 & 9456.16 & 10 & 10572.22 & 9353.58 & 1 & 10688.16 \\
\hline 9743.56 & 1 & 10260.38 & 9563. 89 & 1 & 10453. 13 & 9454.67 & 1 & 10573.88 & 9353. 04 & & 10688.78 \\
\hline 9715.32 & & 10290.20 & 9562. 75 & $1 d ?$ & 10454.38 & 9454.08 & 1 & 10574.54 & 9345.48 & 15 & 10697. 43 \\
\hline 9701.41 & & 10304.95 & 9557. 31 & 3 & 10460.33 & 9445.98 & 1 & 10583.61 & 9344.16 & 5 & 10698. 94 \\
\hline 9680.37 & 1 & 10327. 35 & 9556.11 & 1 & 10461. 64 & 9444.47 & 1 & 10585. 30 & 9343.52 & 2 & 10699.67 \\
\hline 9670.66 & 1 & 10337. 72 & 9553.43 & 4 & 10464.58 & 9443. 32 & 5 & 10586. 60 & 9342.61 & 20 & 10700.72 \\
\hline 9662.30 & 1 & 10346. 67 & 9548. 74 & 1 & 10469. 71 & 9441.06 & 10 & 10589.13 & 9339. 37 & 8 & 10704.43 \\
\hline 9659.81 & 1 & 10349. 33 & 9544. 35 & 3 & 10474. 53 & 9440. 66 & 10 & 10589.58 & 9338. 44 & & 10705. 49 \\
\hline 9645.62 & 1 & 10364.56 & 9543.93 & 7 & 10474.99 & 9437. 73 & 7 & 10592.87 & 9337. 12 & & 10707.00 \\
\hline 9640.73 & $1 w$ & 10369.81 & 9540.90 & 1 & 10478. 32 & 9430.62 & 5 & 10600.85 & 9336. 03 & & 10708. 26 \\
\hline 9637.50 & $1 w$ & 10373. 29 & 9535. 94 & $2 w$ & 10483. 77 & 9428.23 & 20 & 10603.54 & 9334.51 & 3 & 10710.00 \\
\hline 9626.42 & 1 & 10385. 23 & 9528.43 & 1 & 10492. 03 & 9426.87 & 18 & 10605.08 & 9333.55 & 10 & 10711. 10 \\
\hline 9622.72 & 1 & 10389. 22 & 9525.06 & 1 & 10495. 74 & 9421.81 & 1 & 10610. 77 & 9331.51 & 1 & 10713.44 \\
\hline 9621. 25 & 1 & 10390.81 & 9522.27 & 15 & 10498. 82 & 9417. 66 & 3 & 10615. 44 & 9327. 74 & 2 & 10717.77 \\
\hline 9620.01 & 1 & 10392.15 & 9519.31 & 2 & 10502. 09 & 9410.42 & 4 & 10623. 61 & 9325.46 & $5 d ?$ & 10720. 39 \\
\hline 9618. 17 & 1 & 10394. 14 & 9516.99 & 8 & 10504.65 & 9398. 97 & 1 & 10636.55 & 9324.19 & 1 & 10721.85 \\
\hline 9615.50 & 1 & 10397. 03 & 9501.73 & 3 & 10521.52 & 9387. 02 & 1 & 10650. 09 & 9323. 19 & 1 & 10723.00 \\
\hline 9615.03 & 1 & 10397.53 & 9500.92 & 12 & 10522.42 & 9386. 65 & 3 & 10650.51 & 9319. 07 & 2 & 10727. 74 \\
\hline 9610.05 & 1 & 10402.92 & 9497. 44 & 5 & 10526. 27 & 9381. 14 & 15 & 10656. 76 & 9316.84 & 5 & 10730. 31 \\
\hline 9605.12 & $1 w$ & 10408. 26 & 9494. 31 & 10 & 10529.74 & 9379. 60 & $<1$ & 10658. 51 & 9316.24 & 2 & 10731.00 \\
\hline 9592.53 & 1 & 10421. 92 & 9493. 44 & 1 & 10530. 70 & 9377. 67 & 12 & 10660. 71 & 9315.96 & 1 & 10731. 33 \\
\hline 9591. 23 & 1 & 10423. 34 & 9481.67 & 15 & 10543. 78 & 9371.45 & 20 & 10667. 78 & 9315.15 & 1 & 10732. 26 \\
\hline . 9590. 14 & 1 & 10424.52 & 9480.27 & 5 & 10545. 33 & 9369. 39 & 6 & 10670.13 & 9309. 44 & - & 10738. 84 \\
\hline 9589.06 & 1 & 10425.69 & 9479. 19 & $<1$ & 10546.53 & 9366. 41 & 4 & 10673.52 & 9308. 09 & $4 d ?$ & 10740.40 \\
\hline 9581.12 & 3 & 10434. 33 & 9474.47 & 1 & 10551. 79 & 9364.83 & $3 w$ & 10675.32 & 9303. 76 & 1 & 10745.39 \\
\hline 9579.94 & $1 w$ & 10435. 62 & 9469.39 & 2 & 10557. 45 & 9358. 65 & 5 & 10682.37 & 9300.88 & & 10748. 72 \\
\hline 9571.31 & & 10445.03 & 9468.64 & 1 & 10558. 29 & 9357.81 & 5 & 10683. 33 & 9300.35 & & 10749.33 \\
\hline
\end{tabular}


the band at $0.93 \mu$, they were read directly from the table; for the $1.15-\mu$ band, they were interpolated by the procedure described by H. D. Babcock [16].

The second columns of tables 1 and 2 contain the intensities of the band lines as based on visual estimates. A comparison of these estimates for the fainter lines with those made by Babcock and Moore [17] for the same lines in the solar spectrum shows that on the average those marked $<1,1$, and 2 correspond, respectively, to the solar estimates 25,40 , and 50 . For the stronger lines, no reliable correlation with the solar intensities is feasible because of blending; but it is evident from the above comparison that the fainter members of the bands cannot be expected to appear in the laboratory spectra. The letters $w$ and $d$ after the intensities of some of the lines indicate that they are wide, probably unresolved pairs or pairs on the verge of resolution.

In the solar spectrum, the water-vapor lines are greatly widened owing to the long light path in the earth's atmosphere, so that most of them are affected by blending with other lines of terrestrial or solar origin. However, for some of the fainter lines the effects of blending are very slight or absent. The wavelengths measured for such lines in the solar and in the laboratory spectra, as given in tables 1 and 2 , are in very good agreement. On the other hand, a comparison of the wavelengths recorded in this paper with those published by Lueg and Hedfeld show marked differences. These investigators followed an experimental procedure essentially the same as that described in this paper. However, their wavelengths for the stronger lines in the $1.13-\mu$ band are, on the average, $0.16 \mathrm{~A}$ shorter than those of table 1 , whereas those they give for the $0.93-\mu$ band are longer than the wavelengths of table 2 by $0.16 \mathrm{~A}$. The cause of the discrepancy between the two sets of measurement is not apparent.

\section{References}

[1] S. P. Langley, Ann. Astrophys. Observ. Smithsonian Inst. 1, 200 (1900).

[2] W. Herschel, Phil. Trans. Roy. Soc. London 90, 284 (1800).

[3] S. Lamansky, Ann. Physik [II] 146, 200 (1872).

[4] W. de W. Abney and E. R. Festing, Proc. Roy. Soc. (London) 35, 80 (1883).

[5] G. Hettner, Ann. Physik [IV] 55, 492 (1918).

[6] F. E. Fowle, Astrophys. J. 35, 151 (1912).

[7] W. F. Meggers, Astrophys. J. 47, 1 (1918).

[8] K. Burns, Lick Observ. Bul. 10, 64 (1920).

[9] F. S. Brackett, Astrophys. J. 53, 121 (1921).

[10] W. F. Meggers and C. C. Kiess, BS J. Research 9, 309 (1932) RP 473.

[11] E. K. Plyler, J. Research NBS 48, 221 (1952) RP2309.

[12] R. Mecke, Z. Physik. 81, 313 and 445 (1933).

[13] P. Lueg and K. Hedfeld, Z. Physik. 75, 512 (1932).

[14] W. S. Benedict, Phys. Rev. 74, 702, 703, and 1246 (1948); NBS Report 1123 to Office of Naval Research.

[15] S. M. Burka, J. Franklin Inst. 189, 25 (1920).

[16] H. D. Babcock, Phys. Rev. 46, 382 (1934).

[17] H. D. Babcock and C. E. Moore, Carnegie Institution of Washington, Publication No. 579 (1947).

WAShington, January 10, 1952. 